\title{
Correlation between Diabetes Mellitus and Thyroid Dysfunction: Genetic Basis and Literature Review
}

\author{
EKPE, Ekpe Lawson ${ }^{1 *}$
}

1. Dept. Of Chemical Pathology/Immunology, University Of Calabar, Calabar, Nigeria

\begin{abstract}
Background: Co-existence of both thyroid dysfunction and diabetes mellitus is increasing in prevalence and is seen among many patients. The reason for this co-existence is not well known. Many different studies have been performed globally to ascertain this relationship. Aim: The aim of this study was to access the correlation between thyroid dysfunction and Type 1 and 2 diabetes mellitus. Method: Using internet search, a comprehensive literature review was done and words such as diabetes mellitus, thyroid, hypothyroidism, hyperthyroidism, thyroid antibodies, and thyroid problems were searched from Google scholar, Yahoo, PubMed, Medline, Web MD, and Scopus to check for various articles published on any probable link. The references of the relevant articles on this subject were also searched for further information. Results: Analyses of results of various studies from various parts of the world were considered and their prevalence was noted to access the correlation between thyroid dysfunction and diabetes mellitus. Subclinical hypothyroidism is seen as the commonest thyroid problem among female type 1diabetes. Conclusion: There is a strong relationship between thyroid dysfunction and Type 1 and 2 diabetes mellitus.
\end{abstract}

KEYWORDS: Thyroid; Type 1diabetes; Antibodies; Type 2 diabetes; Dysfunction

\section{Introduction}

Thyroid problems/dysfunctions and Diabetes Mellitus (DM) are common endocrine problems encountered by physicians globally (1). It is established repeatedly that there is a deep association and correlation between thyroid dysfunction and DM (2). These findings are consistent from the studies of many

researchers done globally. In this regard, thyroid dysfunction comprises hypothyroidism and hyperthyroidism. Historically, as far back as 1927, Coller and Huggins proved that there was a link between hyperthyroidism and aggravating diabetes mellitus, especially when the DM became complicated. Accordingly,

Corresponding author:

EKPE, Ekpe Lawson

Dept. Of Chemical Pathology/Immunology, University Of Calabar, Calabar, Nigeria

Email: lawsonekpe2002@yahoo.com

Receive date: 2016-01-7| Accept date: 2016-03-15| Publish date: 2016-04-19

DOI: 10.7575/aiac.abcmed.16.04.02.07 
surgical removal of the affected thyroid gland had an improved effect on the hyperthyroid patients who had co-existing DM (3). In many studies, it has been shown that DM and thyroid disorders have been noted to occur simultaneously in some patients (4). Both conditions (diabetes mellitus and thyroid dysfunction) involve a dysfunction of the endocrine system (4). Again, thyroid disorders have a major effect on body glucose regulation and control; and untreated thyroid disorders affect the management of DM patients (4). It is generally reported that DM patients are at an increased risk of thyroid diseases and vice versa. The frequency of thyroid dysfunction in DM patients is higher than in the general population and up to $33 \%$ of patients with Type 2 DM eventually develop thyroid dysfunctions (5). The prevalence of thyroid diseases in DM patients is 2-3 times higher than non-diabetic subjects. Thyroid disorders are known to increases with age and are strongly influenced by female gender, and autoimmune diabetes 6 .

\section{Epidemiology}

In the general population, about $6 \%$ of people have some forms of thyroid disorders (7). However, the prevalence of thyroid disorders increase to over $10 \%$ or more in people with DM. This is commoner in women as most women with type 1 DM have a $30 \%$ chance of developing auto-immune thyroid diseases (7). Although Type $2 \mathrm{DM}$ is not an autoimmune problem, there have been reports of a higher occurrence of thyroid disease, especially hyperthyroidism among people with Type 2 DM (7). The Wickham survey reveals that the prevalence of thyroid dysfunction in male adults in England was 6.6\% (8). According to the National Health and Nutrition Examination Survey (NHANES 111 Study), hypothyroidism and hyperthyroidism were reported to have prevalence of $4.6 \%$ and $1.3 \%$ of the total participants, respectively (9). A prevalence of $12.3 \%$ for thyroid dysfunction in
DM patients was reported in Greece and $16 \%$ in Saudi-Arabia (10). The frequency of thyroid disorder is higher with advancing age. Reports have it that the prevalence of thyroid disorders in diabetic population was reported to be $13.4 \%$ with higher prevalence $(13.4 \%)$ in female Type $1 \mathrm{DM}$ as compared to $6.9 \%$ in male Type 2 DM (11).

Materials and Methods: This study involved a comprehensive literature search from various journals online. This involved search engines as Google Scholar, PubMed, Yahoo, etc. Various journals were searched to include information from various parts of the world. References included in the main articles were also searched for relevant information and data. Data collected were analyzed for relevant information on thyroid dysfunction and diabetes mellitus.

\section{Literature Review}

Sanchez-Lugo reported a total of 78 patients who had Type $1 \mathrm{DM}$ and were confirmed to have thyroid dysfunction. $15 \%$ had thyroid auto-immunity while $40 \%$ had goiter $(p<0.001)$ and more than $75 \%$ were females. This was the lowest prevalence of thyroid autoimmunity in diabetic children among the Hispanic group in USA (12). Radaideh et al. conducted an investigation into the prevalence of thyroid dysfunction and autoimmunity in Type 2 DM in Jordan and recruited students over a 6 month period. $5.9 \%$ of the DM patients had thyroid disorders before this study. However, this study was able to diagnose $6.67 \%$ fresh cases of thyroid disorders among the diabetics. Thus, the total prevalence of thyroid disorder was $12.5 \%$, with subclinical hypothyroidism being the most common presentation. Positive thyroid peroxidase antibody (TPO) was detected in $8.3 \%$ of Type 2 DM patients versus $10.3 \%$ in the control group. Positivity for both TPO antibodies and thyroglobulin antibodies ( Tg ab) was found to be $2.5 \%$ in Type 2 DM (13). Cardoso et al. carried out a study on the 
prevalence of thyroid antibodies in the African diabetic population with both type 1 and type 2 DM. $46 \%$ of the Type 1 DM patients had significant levels of serum thyroid auto antibodies. $8.3 \%$ of patients had subclinical hypothyroidism in Type 2 DM, while $21 \%$ had subclinical hypothyroidism in Type 1 DM patients14. Akbar et al. investigated the observation between thyroid dysfunction in Type 2 DM patients of Saudi origin. They concluded that thyroid dysfunction autoimmunity is common in type 2 diabetes. Thyroid dysfunction was $16 \%$ with GAD65 antibodies in $20 \%$ of Type 2 DM patients. Rodrigues studied a group of individuals to study the prevalence of thyroid dysfunction and anti-thyroid antibodies in Type 1 DM and their first degree relatives. They found that the prevalence of autoimmune thyroid diseases (AITD) among diabetic patients was 35.5\% which was higher among the first degree relatives of diabetics than among relative of diabetics without auto immune thyroid disease (AITD) (15). Similarly, Ghawil et al. defined the prevalence of thyroid autoimmune disease among the patients with type $1 \mathrm{DM}$ in Libya. They found that the major thyroid pathology was subclinical hypothyroidism (2.3\%). About $23.4 \%$ of their patients had positive thyroid peroxidase (TPO) antibodies, while $7.8 \%$ had $\mathrm{Tg}$ antibodies. Most of the affected patients were females and $57 \%$ of these patients had type 1 DM for more than 5 years (16). In the literature, three cases of diabetic ketoacidosis initiated by thyrotoxicosis in young women with type $1 \mathrm{DM}$ have been reported, all of which were diagnosed with Grave's disease (17). Hansen et al. performed a prospective study of thyroid function, morphology and autoimmunity in young patients with type $1 \mathrm{DM}$. They found thyroid ultrasonographic abnormalities with high thyroid auto-antibodies among these patients (18). Holl showed that there was an elevated thyroid antibodies expressed in type 1
DM patients. Thyroid autoimmunity was found in patients with HLA Types DR3 and DR4 (19).

Perros et al. in their study involving type 1 DM and type 2 DM patients found that the incidence of thyroid dysfunction was high in diabetic but highest in female type 1 DM patients and lowest in type $2 \mathrm{DM}$ male patients (20). Also, a retrospective study by Demitrost and Ranabir concluded that type $2 \mathrm{DM}$ is a major growing problem and that type 2 DM patients develop thyroid dysfunction later in life (21).

Papazinfiropoulou et al. carried out a similar study to determine the prevalence of thyroid dysfunction among type 2 DM patients attending out-patient clinics. The prevalence was $12.3 \%$ with an excess of female patients taking the lead in comparison with normal groups $(p<0.001)$. Patients with thyroid dysfunction also had high body mass index (BMI) and high density lipoprotein (HDL) cholesterol, in comparison to patients without thyroid dysfunction (22). Also, Diezz et al. found that diabetic patient with thyroid dysfunction in their study had a prevalence of 9.7\% (95C1, 6.5$13.0 \%)$. The Wickman study, conducted in the late 1970s in England, reported a prevalence of $6.6 \%$ of thyroid dysfunction in adult general population $(24,25)$. The Colorado thyroid disease prevalence study found $9.5 \%$ of the studied population to have elevated thyroid stimulating hormone (TSH) while $2.2 \%$ had low $\operatorname{TSH}(25,26)$.

The NHANESS study in the US population reported hyperthyroidism in $1.3 \%$ of subjects and further observed an increased frequency of thyroid dysfunction in diabetic subjects when compared to individuals without diabetes (25, 27).

Clinical Implication of Co-existence of Diabetes Mellitus and Thyroid Dysfunction Both diabetes mellitus and thyroid conditions involve a dysfunction of the endocrine system $(1,4$, 


\begin{tabular}{llll}
\hline i/N & AUTHOR/YEAR/LOCATION & TYPE OF DIABETES STUDIED & MAJOR THYROID PATHOLOG \\
\hline L. & CARDOSO C. et al. & TYPE 1 DM & SUBCLINICAL \\
& & TYPE 2 DM & HYPOTHYROIDISM FOUND \\
& (NIGERIA) & & 21\% TYPE 1 DM and 8.3 \\
& & & TYPE 2 DM patients \\
$2 . \quad$ RADAIDEH AR et al. (2014) & TYPE 2 DM & SUBCLINICAL \\
& & & HYPOTHYROIDISM (4.1\%) \\
& (JORDAN) &
\end{tabular}

3. AKBAR DH et al.

(SAUDI ARABIA)

t. RODRIGUES et al.

(PORTUGAL)

;. GHAWIL M et al.

(LIBYA)

j. HANSEN D et al.

(2003)

DENMARK

7. RADAIDEH AR (2002)

(JORDAN)

3. KADIYALA R. (UNITED KINGDOM)

). HOLLRW. (GERMANY)

10. CHAOXUN WANG (2013) ( CHINA)
TYPE 2 DM

TYPE $1 \mathrm{DM}$

TYPE 1 DM

TYPE 1 DM

TYPE 1 DM
TYPE 1 DM

TYPE 1 DM

TYPE 2 DM

AUTOIMMUNE
DISEASE (AITD)

SUBCLINICAL

HYPOTHYRIODISM (2.3\%)

OVER HYPERTHYRIODISM

(0.9\%)

SUBCLINICAL

HYPERTHYROIDISM (0.9\%)

OVER HYPERTHYROIDISM

(0.9)

AUTO IMMUNE THYROID

DISEASE

\section{SUBCLINICAL \\ HYPOTHYROIDISM \\ OVERT HYPETHYROIDISM}

BASIC FINDINGS

Females commonly

affected while $46 \%$ had

serum thyroid auto antibodies

Thyroid peroxidase antibody (TPO ab) 8.3\% thyroglobalin ab (Tg ab) $-2.5 \%$

prevalence of thyroid dysfunction was $12.5 \%$ $16 \%$ had thyroid dysfunction.

GAD 65 ab were in $26 \%$ DM

Thyroid autoimmunity was $10 \%$

$35 \%$ of type 1 DM had auto immune thyroid disease (AITD) 23.4\% had positive TPO ab

$7.8 \%$ had $\mathrm{Tg}$ ab 6.99. had both TPO and Tg abs $66.6 \%$ were females

$57 \%$ had DM for at least 5 years

Thyroid ultrasonographic abnormalities thyroid autoantibodies $9.2 \%$ had thyroid auto antibodies

$6.6 \%$ were TPO $-a b$ positive $2.6 \%$ were Tab, TPo $a b$, AMA, and Tg ab positive Increased frequency of thyroid dysfunction Elevated hyperthyroidism. Thyroid auto immunity higher in patients with HLA DR3/DR4

Thyroid dysfunction is common in type $2 \mathrm{DM}$ 
11. PERROSS P et al. (SCOTLAND)

12. DEMITROST L AND

RANABIR S (2012)

( INDIA)
TYPE 1 DM AND TYPE 2 DM

TYPE 2 DM

TYPE 2 DM

13. PAPAZAFIROPOUPOU $A$ et al. (2010)

(GREECE)

44. DIEZ JJ et al. (2011)

(SPAIN)

15. LINBERG B et al.

(SWEDEN)

\author{
SUBCLINICAL \\ HYPOTHYROIDISM (4.8\%) \\ HYPOTHYROIDISM (0.9\%) \\ HYPERTHYROIDISM (0.5\%) \\ SUBCLINICAL \\ HYPERTHYROIDISM (0.5\%) \\ SUBCLINICAL \\ HYPOTHYROIDISM
}

prevalence of thyroid disease $13.4 \%$, highest in type $1 \mathrm{DM}$ females with a rate of $31.4 \%$ and lowest in type $2 \mathrm{DM}$ males, with a rate of $6.9 \%$

Presence of thyroid dysfunction is $31.2 \%$ in Females. DM patients are at higher risk. Most affected patients are $>$ 45 years. Patient with $\mathrm{BMI}>25$ are at higher risk.

Prevalence of thyroid dysfunction is $12.3 \%$.

OVERT HYPERTHEROIDISM Thyroid dysfunction was (3.5\%). SUBCLINICAL in $32.4 \%$ and newly HYPOTHYROIDISM (3.1\%) diagnosed thyroid dysfunction in $9.7 \%$ of the cases.

TYPE 1 DM
High prevalence of thyroid auto antibodies. Thyroglobolin auto antibodies in $33 \%$ of type 1 DM patients. TPO ab in $38 \%$ of the patients

TABLE1: Table showing a summary of various findings linking thyroid dysfunction and diabetes mellitus from different parts of the world

25). DM and thyroid disorder mutually influence each other (25). Thyroid hormone affects the regulation of carbohydrate metabolism and pancreatic function and on the other hand, diabetes mellitus affects thyroid function tests to a large extent. Increased plasma glucose (Hyperglycemia) is enhanced by hyperthyroidism (29). Hypothyroidism is known to reduce the half life of circulating insulin30. Hyperthyroidism also increases the glucose absorption by the gut through excess thyroid hormones in circulation $(31,32)$. In addition to these, hyperthyroidism enhances endogenous production of glucose through several mechanisms (25). Lipolysis is enhanced in patients with hyperthyroidism; with a resultant effect to cause hepatic gluconeogenesis.

On the other hand, hyperthyroidism causes a reduced rate of liver glucose production and this accounts for the decreased insulin demand in hyperthyroid diabetic patients $(25,33)$.

Effect of Diabetes Mellitus on Thyroid Dysfunction DM patients with hyperthyroidism 
have increased levels of glycemic control difficulty and in a study; thyrotoxicosis was reported to cause diabetic ketoacidosis in DM patients (34). Altered thyroid hormone levels have been observed. For instance, reduced T3 levels have been observed in uncontrolled DM patients. Hypothyroidism enhances susceptibility to hypoglycemia, hence making DM management difficult in susceptible patients.

Generally, DM causes an increased risk of heart diseases. Since hyperthyroidism causes increased heart rate, combination of these will enhance cardiac failure in patients having these combined pathologies (35).

Genetic Basis of Thyroid Dysfunction/Diabetes Link Evidence suggests that there is a link between Type $1 \mathrm{DM}$ and auto-immune thyroid diseases. Human Leucocyte Antigen (HLA) alleles encode within the major histo-compatibility complex (MHC). Chromosomes $6 \mathrm{p} 21$ have been recognized for several years being present in both Type $1 \mathrm{DM}$ and AITD. HLA class 11 (HLA-DR) presents peptide antigens to T-cell, and HLA-DR3 allele is significantly associated with Type $1 \mathrm{DM}$ and AITD 36. Also, a number of genes have recently been suggested to be associated with an increased rate of both conditions. The various loci have been identified: CTLA 4(on chromosome 2q33), PTPN 22 (1p13), IFIH1 (2q24), CD25 (10q15), C12ORF30 (12q 24), ERBB3 (12q13), PTPN 2 (18p11), KIAA0350 (16p13), CD226 (18q22); INS (11p15), FCRL3 (1q23), and TSH receptor (14q 131) 37. Some studies have also identified various genes which are identified with gluconeogenesis, glycogen metabolism and insulin signaling. These genes are glucose-6-phospate protein kinase (AKT2), beta-adrenergic receptors, inhibitory $\mathrm{G}$ protein (Gi), phosphoenol pyruvate kinase (PEPCK), pyruvate carboxylase (PC), GLUT $(22,39)$, malic enzyme $(2,39)$ and carbohydrate response element binding protein (39). Again, some other authors have linked at least four shared genes acknowledged to confer risk of development of both AITD and Type 1 DM. They are HLA 19, CTLA-440, PTPN2241, and FOXP3 genes (36).

\section{Conclusion}

The review of literature of many studies all over the world concludes that thyroid dysfunction and diabetes mellitus co-exist in some patients. This has a major negative effect on DM glycemic control and increases the potential for diabetic complications. Regular screening is, therefore, recommended to allow for earlier detection, preferably screened every 1 year for Type 1 DM and every 5 years for Type 2 DM. More research is needed to evaluate this association. Probably, patients with DM (Type 1 or Type 2) should be screened for thyroid dysfunction as frequently as possible.

Conflict of Interests: The author declares he has no conflict of interest to report.

\section{References}

1. Akbar DH, Ahmed MM, Al-Mugalis J. Thyroid dysfunction and thyroid autoimmunity in Saudi Type 2 diabetes. Acta Diabetol 2006; 43(1): 14-8.

2. Wang Chaoxun. The Relationship between Type 2 diabetes mellitus and related thyroid disease. J Diabetes Res. $2013 ; 390534$.

3. Collar FA, Huggeri CB. Effects of hyperthyroidism upon diabetes mellitus striking improvement in diabetes mellitus from thyroidectomy. Am Surg 1927; 86(6): 877-84. 
4. Diabetes:.www.gotendo.com/conditions we treat .aspx

5. Kadiyala R, Peter R, Okosiere OE. Thyroid dysfunction with diabetes: Clinical implication and screening strategies. Int J Chin Pract 2010; 64(8): 1130-9.

6. Vondra K, Vrbikora J, Dvorakoha K. Thyroid gland disease in adult patients with diabetic mellitus. Minerra Endocrinol 2005; 30(4): 217-36.

7. Thyroid disorder and diabetes: www.diabetesselfmanagement.com

8. Mirella Hage, Mira Zantout, Sani Azar. Thyroid disorder and diabetes mellitus. Journal of thyroid research 2011; PMC 31339205.

9. Hollowell JG, Staehling WW, Flanders Dana et al. senum TSH, T4, and thyroid antibodies in the United States population (1988 to 1999): National Health and Nutritional Examination Survey (NHANES) 111). Journal of clinical endocrinology and metabolisms 2002; 87(2): 483-499.

10. Akbar DH, Ahmed MM, Al-Mugalis J. Thyroid dysfunction and thyroid autoimmunity in Saudi Type 2 diabetes. Acta Diabetol 2006; 43(1): 14-8.

11. Perros $P$, McMcrimmin RJ, Shau G, Fier BM. Frequency of thyroid dysfunction in diabetic patient: value of annual screening: Diabet Med 1995; 12(7): 622-7.

12. Sanche Lugo F. Prevalence of thyroid autoimmunity in insulin dependant diabetes mellitus in the Bayamon region. Bol Ass. Med PR 1991; 83-7.

13. Radiadeh AR, Nursier MK, Amani FL, Bateiha et al. Thyroid dysfunction in patients with Type 2 Diabetes Mellitus from Jordan. Saudi Med J 2004; 25(8): 1046-50.

14. Cardoso C, Ohwovoriole AE, Kusku SF. A study of thyroid function and prevalence of thyroid antibodies in an African diabetic population. J Diabetic Complications 1995; 9(1): 37-41.

15. Rodrigues R, Goncalves FT, Jorge PT. Prevalence of thyroid dysfunction and antithyroid antibodies in Type 1 diabetic mellitus patients and their first degree relatives. Arch. Endocrinol. Metab. 2015;59 (2).

16. Ghawil M, Tonutti E, Abusrewil S, Visentin D, et al. Autoimmune thyroid disease in Libyan children and young adults with Type 1 DM. Eur J Pediatr 2011; 170(8): 983-7.

17. Sola E, Morillas C, Garzon S, Gomez - Balaguer M, Hernadez - Mijares A. Association between diabetic ketoacidosis and thyrotoxicosis. Acta diabetologia 2002; 39(4):235-237

18. Hansen M,Bennedbeck FN,Foir-Madsen M, Hegedus L, Jacobsen BB. A prospective study of thyroid function, morphology and autoimmunity in young patients with Type 1 diabetes. Euro J Endocrinol 2003; 148(2): 245-51.

19. Holl Row, Bohm B, Lous U, Grabert M, Hienze E, Homok J. Thyroid auto immunity in children and adolescents with Type 1 DM. Effect of age, gender and HLA Type. Horm Res 1999; 52(3): 113-8.

20. Perros $P$, McCrrimmon RJ, Sheur G, Frier BM. Frequency of thyroid dysfunction in diabetic patients: value of annual screening. Diabetic Medicine 1995; 12(7): 622-627

21. Damitrost L, Ranabir S.Thyroid dysfunction in Type 2 Diabetic mellitus: A retrospective study. Indian journal of endocrimology and metabolism 2012; 16(2): 5334-5335.

22. Papazafiropoulou A, Sotiropoulous A, Kikulaki A, Kardara M, et al. prevalence of thyroid dysfunction among Greek Type 2 Diabetes patients attending an out-patient clinic. J Clin Med Res. 2010; 2(2): 75-78.

23. Diez JJ, Sanchez P, Iglesians P. Prevalence of thyroid dysfunction in patients with Type 2 Diabetes. Esp. Clin Endocrinol Diabetes 2011;119(4): 201-7.

24. Mirella Hage, Mira Zantout, Sani Azar. Thyroid disorder and diabetes mellitus. Journal of thyroid research 2011,PMC 31339205.

25. Tunbridge WMG, Evered DC, Hall R. The spectrum of thyroid disease in a community: the Wickman survey. Clinical Endocrinology 1977;481-493. 
26. Canaris GJ, Manowitz NR, Mayor G, Ridgway EC. The Colorado thyroid disease prevalence study. Ann Intern Med. 2000; 160(4): 526-34.

27. Hollowell JG, Staehling WW, Flanders Dana et al. senum TSH, T4, and thyroid antibodies in the United States population (1988 to 1999): National Health and Nutritional Examination Survey (NHANES) 111). Journal of clinical endocrinology and metabolisms 2002; 87(2): 483-499.

28. Gray RS, Irvine WJ, Clark BF. Screening for thyroid dysfunction in diabetes: Britishl Medical Journal. 1979; 2(6202): 1439.

29. Maxon HR, Krienes KW, Goldsmith RE, Knowles HC. Long term observation of glucose tolerance in thyrotoxcosis patients. Achive of Internal Medicine 1975;135(11): 1477-1480.

30. Dimitriadis G, Baker H, Marsh H, et al. Effect of thyroid hormone excess on action, secretion and metabolism of insulin in humans. The American Journal of Physiology 1985; 248(5): E593-E601.

31. Levin RJ, Smyth DH. The effect of thyroid gland on intestinal absorption of hexoses. The Journal of Physiology1963;(169): 755-769.

32. Malty AS, Sechadin B. The effect of thyroxine on the isolated rat intestine. Gut 1965. Vol. 6 pp 200-202.

33. Okijima F, Ui M. Metabolism of glucose in hyper- and hypothyroid rats in vivo. Glucose turnover values and futile cycle activities obtained with $14 \mathrm{C}$ and 3H- labelled glucose. Biochemical Journal 1979; 182(2): 566-575.

34. Bhattacharyya A, Wiles G. Diabetic ketoacidosis precipitated by thyrotoxocosis. Post Graduate Medical Journal1 1999;75 (883): 291-292.

35. Thyroid disorder and diabetes: www.diabetesselfmanagement.com

36. Villano MJ, Huber AK, Greenberg DA, et al. Autoimmune thyroiditiss and diabetes: Dissecting the joint genetic susceptibility in a large cohort of multiple families. Journal of clinical endocrinology and metabolism 2009;94:14581466.

37. Pearce SH, Merriman TR. Genetics of Type 1 DM and auto-immune thyroid disease. Endocrinol Metab Clin North Am 2009;38(2):289-301.

38. Weistein SP, O'Boyle E, Fisther M, Haber SR. Regulation of GLUT 2 glucose transport expression in liver by thyroid hormone: Evidence of journal regulation of the hepatic glucose transport system. Endocrinology 1994: 135(2): 649-54.

39. Gauther K, Billon C, Bissler M, Lobaccaro JM, Vanacker JM, Samanut J. Thyroid hormone receptor beta (TR Beta) and liver $X$ receptor (LXR) regulates carbohydrate response element - binding protein (CHRE BP) expression in a tissue-selective manner. J Biol Chem 2010;285(36): 28156-63.

40. Ikegani H, Awata T, Kawasak E. et al. The association of CTLA-4 polymorphism with Type 1 Diabetes is concentrated in patient complicated with autoimmune thyroid disease. A multicentric collaborative study in Japan. Journal of clinical endocrinology and metabolism 2006; 91(3): 1087-1092.

41. Kawusaki E, Awata T, Ikegani H. Systematic search for single nucleotide polymorphism in a lymphous tyrosine phosphatase gene (PTPN22): Association between a parameter polymorphissm and Type 1 Diabetes in Asian population. American journal of medical genetics 2006; 140(6): 586-593. 